\title{
Interaction of Recombinant Apolipoprotein(a) and Lipoprotein(a) with Macrophages
}

Thomas F. Zioncheck, “ Lyn M. Powell, ${ }^{\star}$ Glenn C. Rice, ${ }^{\star}$ Dan L. Eaton, ${ }^{\star}$ and Richard M. Lawn*

*Department of Cardiovascular Research, ${ }^{\ddagger}$ Department of Immunology Research and Assay Technology,

Genentech, Inc., South San Francisco, California 94080

\begin{abstract}
Elevated plasma levels of lipoprotein(a), Lp(a), represent a major, inherited risk factor for coronary heart disease, although the mechanism of its action remains unknown. $L p(a)$ is distinguished from the related LDL particle by the addition of apolipoprotein(a), apo(a). The presence of this large glycoprotein is likely to affect the binding of the particle to the LDL receptor and/or other receptors which may contribute to the atherogenic potential of $L p(a)$. Here we demonstrate the binding to macrophages of $L p(a)$ and pure recombinant apo(a) protein, via a specific, high-affinity receptor. This binding could lead to foam cell formation and the localization of $L p(a)$ to atherosclerotic plaques. (J. Clin. Invest. 1991. 87:767-771.) Key words: Lp(a) - atherosclerosis • foam cells
\end{abstract}

\section{Introduction}

Plasma levels of lipoprotein(a), Lp(a), ${ }^{1}$ correlate strongly with atherosclerosis, and elevated $\mathrm{Lp}(\mathrm{a})$ is an independent risk factor for coronary heart disease (see reference 1 for review). Plasma $\mathrm{Lp}(\mathrm{a})$ levels are essentially determined by inheritance and are relatively resistant to diet and drug manipulations. $\mathrm{Lp}$ (a) closely resembles LDL in lipid composition and the presence of apolipoprotein B-100 (apo B-100), but also contains a highly glycosylated protein, apolipoprotein(a), apo(a), covalently linked to apo B-100 (1). The presence of this additional charged moiety could have an effect on the binding of the particle to receptors which are significant in the metabolism of LDL. Sequence determination revealed that apo(a) contains remarkable similarity to plasminogen, consisting primarily of numerous repeats which resemble the fourth kringle domain of plasminogen $(2,3)$. Apo(a) is a large glycoprotein exhibiting numerous size isoforms ranging from $\sim 400$ to $800 \mathrm{kD}$ which are due to differing numbers of kringle repeats (4-6). The presence of $\mathrm{N}$ - and $\mathrm{O}$-linked glycosylation sites in each kringle give apo(a) a high carbohydrate content and negative charge $(3,7$, 8 ). Recently we have cloned and expressed in cultured mammalian cells a recombinant apo(a) isoform that has a predicted

Address reprint requests to Dr. Richard M. Lawn, Division of Cardiovascular Medicine, Stanford University School of Medicine, 300 Pasteur Drive, Stanford, CA 94305-5246.

Received for publication 22 August 1990 and in revised form 17 October 1990.

1. Abbreviations used in this paper: apo(a), apolipoprotein(a), apo B-100, apolipoprotein B-100; Lp(a), lipoprotein(a).

J. Clin. Invest.

(C) The American Society for Clinical Investigation, Inc.

0021-9738/91/03/0767/05 \$2.00

Volume 87, March 1991, 767-771
$M_{\mathrm{r}}$ of 250,000 but migrates on reducing SDS-PAGE at $\sim 500,000$ (M. L. Koschinsky, J. E. Tomlinson, T. F. Zioncheck, K. Schwartz, D. L. Eaton and R. M. Lawn, submitted for publication). Carbohydrate composition and isoelectric focusing analyses indicate that the recombinant molecule is highly glycosylated and negatively charged, as is its natural counterpart, and retains the lysine binding properties of $\mathrm{Lp}(\mathrm{a})$. Availability of this pure molecule allows us to investigate the effect of the apo(a) protein on ligand interaction unencumbered by the problems of working with the plasma-derived lipoprotein, such as aggregation and purity. Furthermore, the recombinant-derived apo(a) need not be subject to the reducing conditions utilized to purify it from the $\mathrm{Lp}(\mathrm{a})$ lipoprotein, avoiding partial denaturation and misfolding, which appear to affect some of its binding properties. A significant proportion of the cells in early fatty streak lesions of atherosclerosis are lipid-laden foam cells. Foam cells derive from the deposition of large amounts of cholesterol into monocyte-derived macrophages and arterial smooth muscle cells (see references 9 and 10 for review). The largest potential source of plasma cholesterol is LDL. However, macrophages in culture do not ingest large amounts of LDL, due to the stringent regulation of LDL receptor activity by cellular cholesterol content. Macrophages can ingest lipoproteins by several other receptor- and nonreceptor-mediated mechanisms. For example, LDL modified by various means such as oxidation, acetylation, or malondialdehyde treatment is avidly taken up by a distinct receptor (or class of receptors) on macrophages termed the acetyl LDL, oxidized LDL, or scavenger receptors $(9-11)$. These receptors are not regulated by cell cholesterol content and uptake of modified LDL leads to foam cell formation in vitro. A common feature of the modifications of LDL which lead to uptake by the scavenger pathway is a net increase in negative charge. Perhaps $L p(a)$, and LDL-like particle modified by the negatively charged apo(a), could interact with some type of receptor on macrophages. In this paper we have investigated the binding of purified recombinant apo(a) and $\mathrm{Lp}(\mathrm{a})$ isolated from human plasma to cultured mouse macrophage P388D.1 cells.

\section{Methods}

A homogeneous preparation of acetyl LDL was prepared by Biomedical Technologies, Inc. (Cambridge, MA) using excess acetic anhydride according to the method of Goldstein et al. (11). This acetyl LDL is homogeneous and migrates faster than LDL in agarose gel electrophoresis, has $>90 \%$ of lysine residues modified, and binds to mouse peritoneal macrophages, as determined by the manufacturer. LDL and Lp(a) (isoform size of its apo(a) $\sim 700,000 \mathrm{D}$ ) were purified to homogeneity (as determined by silver stained 4-15\% denaturing polyacrylamide gels) from human plasma by $\mathrm{NaBr}$ and $\mathrm{CsCl}$ density gradient centrifugation (12) and plasminogen was purified by lysine-Sepharose chromatography (13). $\mathrm{LDL}$ and $\mathrm{Lp}(\mathrm{a})$ preparations were stored at $4^{\circ} \mathrm{C}$ in $7.5 \%$ $\mathrm{CsCl}, 150 \mathrm{mM} \mathrm{NaCl}, 1 \mathrm{mM} \mathrm{NaN}_{3}, 1 \mathrm{mM}$ PMSF, $1 \mathrm{mM}$ EDTA and used within $3 \mathrm{~d}$. 
Apo(a), Lp(a), and acetyl LDL were biotinylated using biotin- $N$-hydroxysuccinimide ester (Calbiochem-Behring Corp., La Jolla, CA) with a ratio of biotin ester to protein of 1:2.5. A form of apo(a) containing 17 copies of the kringle four-like domain and single copies of its domains which resemble kringle five and the protease of plasminogen was produced in cultured human kidney-derived cells by recombinant DNA techniques and purified to homogeneity (as defined by the presence of a single band in silver-stained SDS-PAGE) by either lysine-Sepharose or monoclonal antibody chromatography (M. L. Koschinsky, J. E. Tomlinson, T. F. Zioncheck, K. Schwartz, D. L. Eaton, and R. M. Lawn, submitted for publication). Protein concentrations determined by the method of Bradford (14).

P388D.1 cells were grown to subconfluence in RPMI-1640 (Gibco, Grand Island, NY) plus $1 \mathrm{mM}$ L-glutamine and $10 \%$ heat-inactivated FBS and harvested by physical dislodging (15). Approximately $5 \times 10^{5}$ cells were incubated with biotinylated substrates in a total volume of 50 $\mu \mathrm{l}$ of PBS containing $2 \%$ FBS for $1 \mathrm{~h}$ on ice. The cells were washed twice with PBS plus $2 \%$ FBS and stained in a similar manner with phycoerythrin conjugated streptavidin (CalTag, South San Francisco, CA). Flow cytometry analysis was performed on either a modified Coulter Electronics 753 (Hialeah, FL) or a Becton Dickinson FACscan (Mountain View, CA) using standard excitation and emission parameters for phycoerythrin (16).

Binding of ${ }^{125}$ I-apo(a) to P388D.1 cells. Recombinant apo(a) was iodinated to a specific activity of $3.5 \times 10^{6} \mathrm{cpm} / \mu \mathrm{g}$ with Iodo-beads (Pierce Chemical Co., Rockford, IL) according to the manufacturer's suggested procedure. Labeled and unlabeled apo(a) were made $10 \%$ in
FBS and then dialyzed against RPMI-1640 before incubation with p388D. 1 cells. $10^{7}$ macrophages were added at $4^{\circ} \mathrm{C}$ to an incubation mixture containing $10^{-10} \mathrm{M}^{125} \mathrm{I}$-apo(a) and a range of unlabeled apo(a) concentrations. Incubations were carried out for $2 \mathrm{~h}$ in $12 \times 75 \mathrm{~mm}$ Falcon tubes which were shaken gently every $10 \mathrm{~min}$ to maintain cells in suspension. Cell bound ${ }^{125} \mathrm{I}$-apo(a) was separated from unbound by overlaying an aliquot of the incubation mixture on a $1-\mathrm{ml}$ cushion of FBS chilled to $4^{\circ} \mathrm{C}$. Cells were pelleted through the FBS by centrifugation at $2,900 \mathrm{~g}$ for $1 \mathrm{~min}$ in a microfuge. Supernatants were aspirated and cell pellets were counted in a gamma counter to determine counts bound. Free radioactivity was determined by subtracting bound from total counts. Nonspecific binding in the presence of 100 to 5,000-fold molar excess of unlabeled apo(a) accounted for $\sim 25 \%$ of total binding, and was subtracted to yield the values of specific binding shown.

\section{Results}

Analysis of the interaction of biotinylated acetyl LDL with P388D.1 cells using the technique of laser scan flow cytometry showed specific binding with concentrations as low as $10 \mathrm{nM}$ biotinylated acetyl LDL (Fig. 1 a). Our results obtained with flow cytometry are comparable to those previously reported by Via and colleagues using iodinated acetyl LDL (15). Specificity was demonstrated by competition with nonbiotinylated acetyl LDL. A 50-fold molar excess of apo(a) effectively prevented the binding of biotinylated acetyl LDL as well.
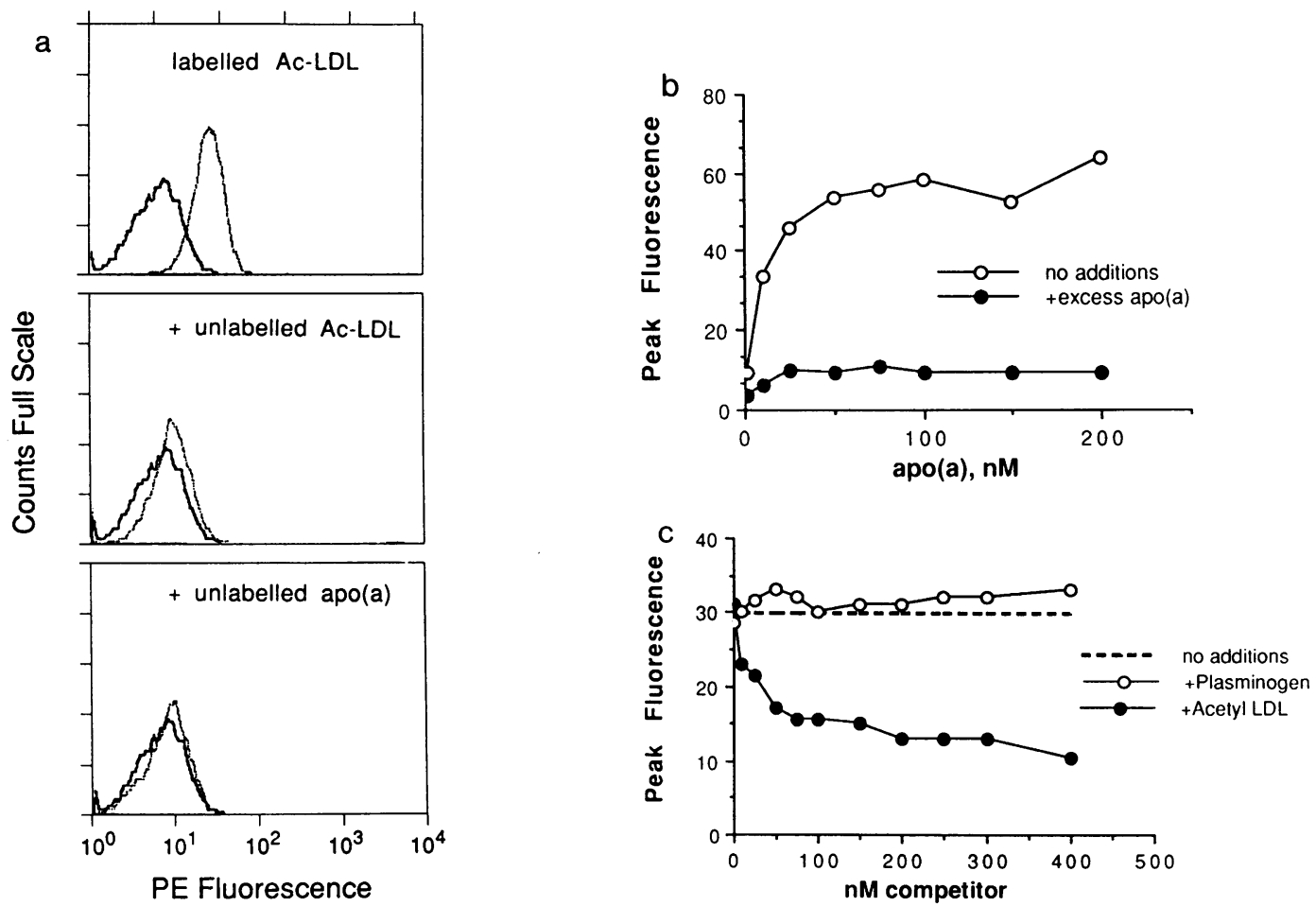

Figure 1. Binding and competition of biotinylated acetyl LDL to mouse P388D.1 cells. (a) FACS frequency histograms. $5 \times 10^{5}$ P388D.1 cells were incubated with $10 \mathrm{nM}$ biotinylated acetyl-LDL and, subsequently, phycoerythrin (PE)-conjugated streptavidin and analyzed by FACS. Top graph shows PE fluorescence vs. cell number for control cells without (solid line) and with (dotted line) biotinylated acetyl LDL which produced an $\sim 10$-fold increase in mean fluorescence. In middle and bottom graphs, the fluorescence shift with biotinylated acetyl LDL was virtually eliminated with the addition of excess unlabeled acetyl LDL or recombinant apo(a), respectively. (b) Binding of biotinylated apo(a). Open circles indicated peak fluorescence of cell populations (such as shown in $a$ ) incubated with increasing concentrations of biotinylated recombinant apo(a). Solid circles indicate peak fluorescence of cells incubated with biotinylated apo(a) in the presence of 50-fold excess of unlabeled apo(a) as a measure of nonspecific fluorescence. (c) Competition of apo(a) binding by acetyl LDL but not by plasminogen. Binding of $10 \mathrm{nM}$ biotinylated apo(a) was measured by fluorescence without competitors (dash) or in the presence of increasing concentrations of acetyl LDL (solid circle) or plasminogen (open circle). 

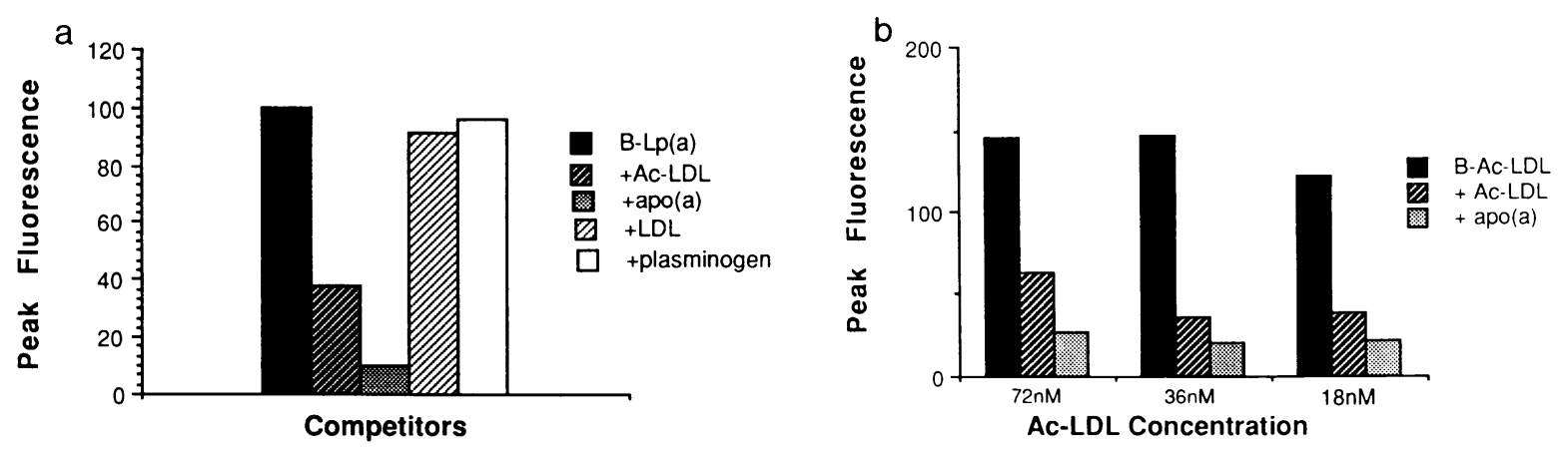

Figure 2. Binding of biotinylated Lp(a) and acetyl LDL. (a) Binding and competition of $\mathrm{Lp}(\mathrm{a})$. Biotinylated human $\mathrm{Lp}(\mathrm{a})$ [B-Lp(a)] at $10 \mathrm{nM}$ was incubated with P388D.1 cells alone (solid bar) or with 50-fold excess of unlabeled competitors and peak fluorescence was measured by flow cytometry. Acetyl LDL and apo(a), but not LDL or plasminogen competed effectively. (b) Binding and competition of biotinylated acetyl LDL. Peak fluorescence of P388D.1 cells was measured for three concentrations of biotinylated acetyl LDL (B-Ac-LDL) with no competitor added, or in the presence of 50 -fold excess of unlabeled acetyl LDL or unlabeled apo(a).

This result prompted the analysis of the binding of biotinylated apo(a) and $\mathrm{Lp}(\mathrm{a})$ to P388D.1 cells. Biotinylated apo(a) binding was detectable at concentrations of $500 \mathrm{ng} / \mathrm{ml}(1 \mathrm{nM})$ and saturated at $\sim 50 \mu \mathrm{g} / \mathrm{ml}(100 \mathrm{nM})$ (Fig. $1 \mathrm{~b}$ ). The binding of biotinylated apo(a) was dramatically reduced in the presence of excess apo(a), implying specificity. Binding of biotinylated Lp(a) displayed a similar dose dependence (not shown). The binding of apo(a) was markedly inhibited by acetyl LDL but not significantly by plasminogen (Fig. $1 c$ ). Similarly, the binding of the biotinylated lipoprotein $\operatorname{Lp}(\mathrm{a})$ was competed by apo(a) and acetyl LDL, but not by LDL or plasminogen (Fig. 2 a). (Due to aggregation, binding of biotinylated apo(a), as opposed to $\mathrm{Lp}(\mathrm{a})$, appeared to be partially inhibited by LDL.) It seems likely that labeling procedures employed here did not modify the binding characteristics of ligands, because the binding of labeled apo(a) and acetyl LDL is effectively competed for by the unlabeled ligand. We also observed that apo(a) was more potent competitor of labeled acetyl LDL binding than acetyl LDL itself (Fig. $2 b$ ). This higher avidity could be due to the many copies of glycosylated kringle domains present in each molecule of apo(a), and suggests that different isoforms of apo(a) may vary in their binding.

To quantitate the binding of apo(a), the interaction of radioiodinated r-apo(a) with cells was analyzed. ${ }^{125}$ I-labeled apo(a), like the biotinylated protein, has specific and saturable binding to P388D.1 cells (Fig. 3). Scatchard analysis of the data indicates a single binding site with $K_{\mathrm{d}}=15 \mathrm{nM}$ and $B_{\max }=3.7$ $\times 10^{4}$ binding sites per cell. This compares with $K_{\mathrm{d}}=30 \mathrm{nM}$ of binding of acetyl LDL to this same cell type reported by Via and colleagues (15).

Functional binding of acetyl LDL to macrophages results in uptake and degradation in lysosomes. To determine whether apo(a) could be metabolized by macrophages iodinated $r$ apo(a) was incubated with P388D. 1 cells at $37^{\circ} \mathrm{C}$ in the presence or absence of unlabeled excess r-apo(a). As shown in Fig. 4 $a$, increasing concentrations of iodinated apo(a) produced an increase in acid-soluble label in the media, with saturation at $\sim 40 \mathrm{nM}$. Chloroquine inhibited the response, suggesting that degradation occurred in lysozomes (17). However, the relative rate of degradation of apo(a) was about one-fourth of that observed with acetyl LDL (Fig. $4 b$ ). Thus, we conclude that macrophages are capable of limited uptake and degradation of apo(a) bound at $37^{\circ} \mathrm{C}$.

\section{Discussion}

Previous reports have suggested that native $\mathrm{Lp}(\mathrm{a})$ does not significantly interact with human monocyte-derived or mouse peritoneal macrophages $(18,19)$. The discrepancy of these findings may be due to differences in the origin of cells and preparation of ligands. However, in preliminary experiments, we have detected specific, saturable binding of biotinylated apo(a) to human monocyte-derived macrophage cells (20) kindly provided by Mark Elstad and Stephen Prescott, University of Utah (data not shown). Another contrast between our methods and others is the fact that we have assayed binding to cells in suspension, rather than to cells adherent to plates. Our binding results with $\mathrm{Lp}(\mathrm{a})$ could not have been due to untoward oxidation of lipoproteins, because they were reproduced with lipoproteinfree, recombinant apo(a). (Another group has recently reported in abstract the binding of $\mathrm{Lp}(\mathrm{a})$ to macrophages [21]).

The competition results we present suggest the $L p(a)$ inter-

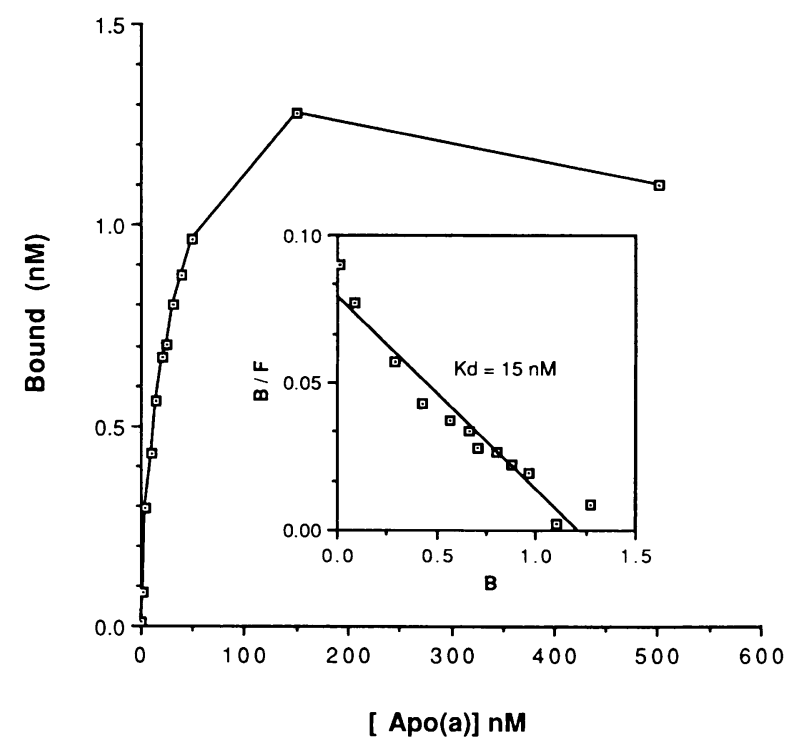

Figure 3. Binding of ${ }^{125} 1$-apo(a) to P388D. 1 cells at $4^{\circ} \mathrm{C}$. Specific binding of recombinant apo(a) to the cultured mouse macrophage was determined as described in Methods. Inset shows a Scatchard plot yielding a $K_{\mathrm{d}}=15 \mathrm{nM}$. 

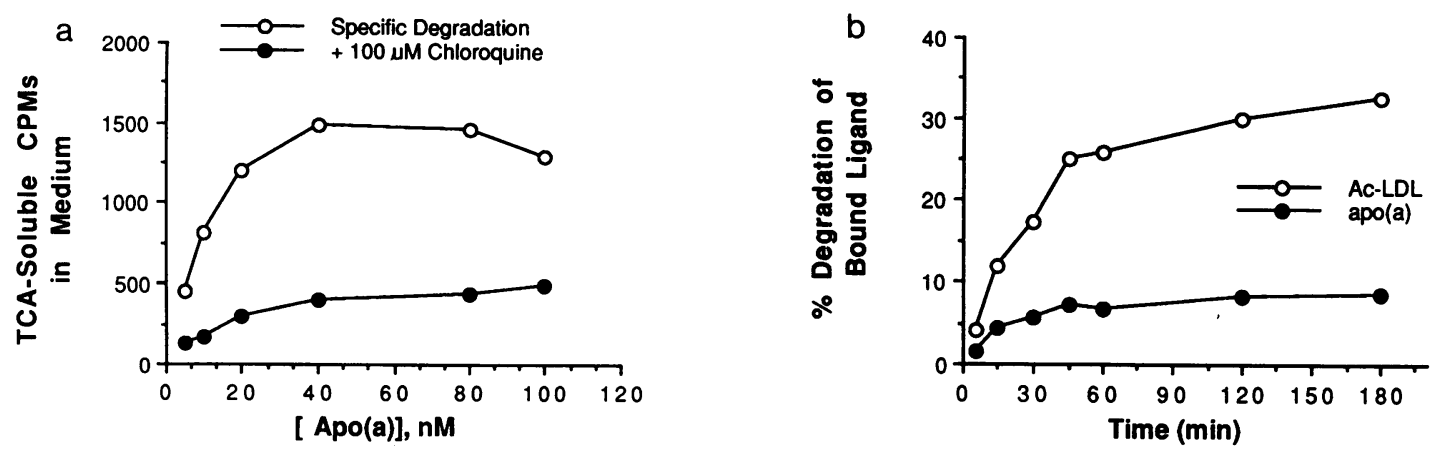

Figure 4. Uptake and degradation of ${ }^{125} \mathrm{I}$-apo(a). (a) $10^{6} \mathrm{P} 388 \mathrm{D} .1$ cells were incubated at $37^{\circ} \mathrm{C}$ in $0.5 \mathrm{ml}$ of RPMI plus $10 \%$ FBS containing increasing concentrations of ${ }^{125} \mathrm{I}$-apo(a) $\left(9 \times 10^{5} \mathrm{cpm} / \mu \mathrm{g}\right)$. Parallel incubations were carried out in the presence of $1 \mu \mathrm{M}$ unlabeled apo(a) to determine nonspecific degradation, which was subtracted. Chloroquine $(100 \mu \mathrm{M})$ was added as an inhibitor of lysosomal degradation (17). Cells were kept in suspension by a tube rocker. After $2 \mathrm{~h}$ incubation, cells were pelleted and unbound apo(a) removed by aspiration. Cells were washed extensively with RPMI plus 10\% FBS before resuspension in fresh media (plus or minus chloroquine) and incubated for an additional 3 $\mathrm{h}$ at $37^{\circ} \mathrm{C}$. Cells were then pelleted and the media precipitated in $10 \%$ TCA overnight on ice. Precipitated protein was removed by centrifugation at $11,600 \mathrm{~g}$ for $5 \mathrm{~min}$ and ${ }^{125} \mathrm{I}$ in the supernatants was counted. (b) P388D.1 cells were incubated with either ${ }^{125} \mathrm{I}$-labeled apo(a) or acetyl LDL $\left(5 \times 10^{5} \mathrm{cpm} / \mu \mathrm{g}\right)(15)$ for $1 \mathrm{~h}$ at $37^{\circ} \mathrm{C}$ and then pelleted, washed and recultured (as described above) for the times indicated. TCA-soluble ${ }^{125} \mathrm{I}$ degradation products in the media were determined and expressed as percent of specific counts bound at the time of reculturing $(t=0)$.

acts with at least one receptor on macrophages which also binds acetyl LDL. Acetyl LDL binds to one or several distinct "scavenger" receptors found on macrophages and nonparenchymal cells of the liver. Our results are most consistent with binding of apo(a) and $\mathrm{Lp}(\mathrm{a})$ to macrophages at physiological concentrations, but with limited efficiency of internalization. This suggests that either the relevant macrophage receptor for $L p(a)$ is not the acetyl LDL scavenger receptor, or that it binds to this receptor in a distinctive manner, so that it is internalized and degraded much more poorly than acetyl LDL. Furthermore, polyinosine, a potent inhibitor of the acetyl LDL receptor, produced a maximum inhibition of biotinylated apo(a) binding of only $\sim 25 \%$ at concentrations ranging from 50 to $200 \mu \mathrm{g} / \mathrm{ml}$ (data not shown). Preliminary results indicate that recombinant apo(a) does not bind avidly to Chinese hamster ovary cells that express two forms of cloned bovine scavenger receptor (22, 23; Krieger, M., personal communication). Several other classes of macrophage lipoprotein receptors have been described. These include a distinct oxidized LDL receptor (24), $\beta$-VLDL receptor (9), and the advanced glycosylation end products (AGE) receptor, which was shown to bind acetyl LDL (25). Whatever macrophage receptor is responsible for the high-affinity binding that we show here, this binding could contribute to the pathophysiology of excess $\mathrm{Lp}(\mathrm{a})$. For even if initial uptake is poor, unmodified $\mathrm{Lp}(\mathrm{a})$ might remain associated with the surface of macrophages and lead to the targeting of $\mathrm{Lp}(\mathrm{a})$ to atherosclerotic plaques, perhaps due to binding to components of extracellular matrix or residual thrombi. Surface binding could also lead to local oxidative modification within the vessel milieu, leading to reactivity with the scavenger receptor, as proposed to occur with LDL (10) and malondialdehydemodified $\mathrm{Lp}(\mathrm{a})$ (19). This scenario is consistent with the fact that unmodified $\mathrm{Lp}(\mathrm{a})$ has a far longer half-life in plasma than acetyl LDL which is rapidly cleared from the circulation by hepatic scavenger receptors.

Our competition results also indicate that this particular binding property of $\mathrm{Lp}(\mathrm{a})$ is not shared with plasminogen, despite the great similarity of amino acid sequence. Plasminogen receptors have been described on endothelial cells and macro- phages (26-28). $\mathrm{Lp}(\mathrm{a})$ binding is not due to this receptor, because we find lack of competition with plasminogen, and because plasminogen binds to its receptor much less avidly (2628) (unless one argues that $\mathrm{Lp}(\mathrm{a})$ is the much preferred ligand of the "plasminogen" receptor). Key differences between apo(a) and plasminogen, such as the negative charge and high degree of glycosylation of apo(a) could account for their distinctive binding properties.

The weight of epidemiologic evidence has almost certainly demonstrated that elevated plasma concentrations of $L p(a)$ are atherogenic. A measurably increased risk of coronary heart disease can be seen with plasma concentrations of $L p(a)$ of $\sim 100$ $\mathrm{nM}$, which is about one-fifth that of comparably pathological levels of LDL (1). Several hypotheses for this effect have been proposed. Three groups have reported that $\mathrm{Lp}(\mathrm{a})$ displaces plasminogen from binding sites on endothelial and U-937 cells (26-28). This suggests that elevated Lp(a) might interfere with fibrinolysis at the cellular level. This result is intriguing when combined with the observation that $\operatorname{Lp}(a)$ does not substantially inhibit clot lysis in the fluid phase $(27,29)$ (although some reports disagree with that analysis [30, 31]). Hence, the nearly $25 \%$ of the population with $\mathrm{Lp}(\mathrm{a})$ levels in the increased risk range do not appear to have gross clotting abnormalities, but may possess increased residual thrombi at the surface of blood vessels which could lead to the gradual development of atherosclerotic lesions.

Lp(a) might also be localized to damaged vessel walls by binding to components of cell matrix or blood clots such as fibronectin (32) or fibrin (33). $\mathrm{Lp}(\mathrm{a})$ has been detected in the intima of atherosclerotic lesions by immunohistochemistry and by the measurement of protein extracted from tissue (34, 35). Although much of the antigen was detected in extracellular regions, some reactivity was seen in macrophage-derived foam cells, despite the fact that its detectability within such cells may be diminished by intracellular hydrolysis. Here we show that $\mathrm{Lp}(\mathrm{a})$ is capable of specific binding to mouse macrophage cells. This could represent a significant route of entry into the vessel media and contribute to the onset of disease. The binding of modified lipoproteins to macrophages may lead to atherogene- 
sis by a number of effects which include foam cell formation and the induction of growth factors, release of arachidonic acid metabolites and increased procoagulant activity $(10,36,37$, 38). In view of $\mathrm{Lp}(\mathrm{a})$ 's potency as a risk factor for this major disease, it remains important to further characterize the interaction of $\mathrm{Lp}(\mathrm{a})$ with macrophages and other cells and macromolecules that are present in the artery wall.

\section{Acknowledgments}

We thank Karen Schwartz for aid in production of recombinant apo(a), Dr. Marlys Koschinsky and Dr. James Tomlinson for their role in establishment of the recombinant apo(a) cell line, and Dr. Mark Elstad and Dr. Stephen Prescott for providing human macrophages.

\section{References}

1. Scanu, A. M., and G. M. Fless. 1990. Lipoprotein(a): heterogeneity and biological significance. J. Clin. Invest. 85:1709-1715.

2. Eaton, D., G. Fless, W. Kohr, J. McLean, Q. Xu, C. Miller, R. Lawn, and A. Scanu. 1987. Partial amino acid sequence of apolipoprotein(a) shows that it is homologous to plasminogen. Proc. Natl. Acad. Sci. USA. 84:3224-3228.

3. McLean, J., J. Tomlinson, W. Kuang, D. Eaton, E. Chen, G. Fless, A. Scanu, and R. Lawn. 1987. cDNA sequence of human apolipoprotein(a) is homologous to plasminogen. Nature (Lond.). 330:132-137.

4. Hixson, J. E., M. L. Britten, G. S. Manis, and D. L. Rainwater. 1989. Apolipoprotein(a) glycoprotein isoforms result from size differences in apo(a) mRNA. J. Biol. Chem. 264:6013-6016.

5. Koschinsky, M. L., U. Beisiegel, D. Henne-Bruns, D. L. Eaton, and R. M. Lawn. 1990. Apolipoprotein(a) size heterogeneity is related to variable number of repeat sequences in its mRNA. Biochemistry. 29:640-644.

6. Gavish, D., N. Azrolan, and J. L. Breslow. 1989. Plasma Lp(a) concentration is inversely correlated with the ratio of kringle IV/kringle V encoding domains in the apo(a) gene. J. Clin. Invest. 84:2021-2027.

7. Fless, G. M., M. E. ZumMallen, and A. M. Scanu. 1986. Physicochemical properties of apolipoprotein(a) and lipoprotein(a-) derived from the dissociation of human plasma lipoprotein(a). J. Biol. Chem. 261:8712-8718.

8. Kratzin, H., V. W. Armstrong, M. Niehaus, N. Hilschmann, and D. Seidel. 1987. Structural relationship of an apolipoprotein(a) phenotype $(570 \mathrm{kDa})$ to plasminogen. Biol. Chem. Hoppe-Seyler. 362:1533-1544.

9. Fogelman, A., B. Van Lenten, C. Warden, M. Haberland, and P. Edwards. 1988. Macrophage lipoprotein receptors. J. Cell Sci. 9(Suppl.):135-149.

10. Steinberg, D., S. Parthasarathy, T. Carew, J. Khoo, and J. Witztum. 1989. Modifications of low density lipoprotein that increase its atherogenicity. $N$. Engl. J. Med. 320:915-924.

11. Goldstein, J. L., Y. K. Ho, S. K. Basu, and M. S. Brown. 1979. Binding site on macrophages that mediates uptake and degradation of acetyl low density lipoprotein, producing massive cholesterol deposition. Proc. Natl. Acad. Sci. USA. 76:333-337.

12. Fless, G. M., C. A. Rolih, and A. M. Scanu. 1984. Heterogeneity of human plasma lipoprotein(a). J. Biol. Chem. 259:11470-11478.

13. Deutsch, D. G., and E. T. Mertz. 1970. Plasminogen: purification from human plasma by affinity chromotography. Science (Wash. DC). 170:10951096.

14. Bradford, M. 1976. A rapid and sensitive method for the quantitation of microgram quantities of protein. Anal. Biochem. 72:248-252.

15. Via, D., A. Plant, I. Craig, A. Gotto, and L. C. Smith. 1985. Metabolism of normal and modified low density lipoproteins by macrophage cell lines of murine and human origin. Biochim. Biophys. Acta. 833:417-428.

16. Woronicz, J. D., and G. C. Rice. 1989. Simple modification of a commercial flow cytometer to triple laser excitation. J. Immunol. Methods. 120:291-196.

17. Goldstein, J. L., G. Y. Brunschede, and M. S. Brown. 1975. Inhibition of protelytic degradation of low density lipoprotein in human fibroblasts by chloroquine, conconavalin A, and triton WR 1339. J. Biol. Chem. 250:7854-7862.

18. Krempler, F., G. Kostner, A. Roscher, K. Bolzano, and F. Sandhofer. 1984. The interaction of human apo-B containing lipoproteins with mouse peritoneal macrophages: a comparison of Lp(a) with LDL. J. Lipid Res. 25:283-287.

19. Haberland, M. E., G. Fless, A. M. Scanu, and A. M. Fogelman. 1989. Modification of Lp(a) by mlondialdehyde leads to avid uptake by human monocyte-macrophages. Circulation. 163(Suppl. II):654. (Abstr.)

20. Elstad, M., D. Stafforini, G. McIntyre, S. Prescott, and G. Zimmerman 1989. Platelet activating factor acetylhydrolase increases during macrophage differentiation. J. Biol. Chem. 264:8467-8470.

21. Plump, A., J. Smith, and D. Gavish. 1990. Lp(a) binding and uptake by macrophages leads to an increased cellular cholesterol content. Clin. Res. 38.2:292a. (Abstr.)

22. Kodama, T., M. Freeman, L. Rohrer, J. Zabrecky, P. Matsudiara, and M. Krieger. 1990. Type I macrophage scavenger receptor contains $\alpha$-helical and collagen-like coiled coils. Nature (Lond.). 343:531-535.

23. Rohrer, L., M. Freeman, T. Kodama, M. Penman, and M. Krieger. 1990 Coiled-coil fibrous domains mediate ligand binding by macrophage scavenger receptor type II. Nature (Lond.). 343:570-572.

24. Sparrow, C., S. Parthasarathy, and D. Steinberg. 1989. A macrophage receptor that recognizes oxidized LDL but not acetyl LDL. J. Biol. Chem. 264:2599-2604.

25. Vlassara, H., M. Brownlee, and A. Cerami. 1986. Novel macrophage receptor for glucose-modified proteins is distinct from previously described scavenger receptors. J. Exp. Med. 164:1301-1309.

26. Miles, L., G. Fless, E. Levin, A. Scanu, and E. Plow. 1989. A potential basis for the thrombotic risks associated with lipoprotein(a). Nature (Lond.) 339:301-303.

27. Hajjar, K. A., D. Gavish, J. L. Breslow, and R. L. Nachman. 1989. Lipoprotein(a) modulation of endothelial cell surface fibrinolysis and its potential role in atherosclerosis. Nature (Lond.). 339:303-305.

28. Gonzalez-Gronow, M., J. M. Edelberg, and S. M. Pizzo. 1989. Further characterization of the cellular plasminogen binding site: evidence that plasminogen 2 and lipoprotein a compete for the same site. Biochemistry. 28:2374-2377.

29. Eaton, D. L., and J. E. Tomlinson. 1989. Does Lp(a) alter fibrinolysis? Circulation. 467(Suppl. II): 1857.

30. Loscalzo, J., M. Weinfeld, G. M. Fless, and A. M. Scanu. 1990. Lipoprotein(a), fibrin binding, and plasminogen activation. Arteriosclerosis. 10:240-245.

31. Edelberg, J. M., M. Gonzalez-Gronow, and S. V. Pizzo. 1989. Lipoprotein(a) inhibits streptokinase-mediated activation of human plasminogen. Bio chemistry. 28:2370-2374.

32. Salonen, E., M. Jauhiainen, L. Zardi, A. Vaheri, and C. Enholm. 1989 Lipoprotein(a) binds to fibronectin and has serine proteinase activity capable of cleaving it. EMBO (Eur. Mol. Biol. Organ.) J. 8:4035-4040.

33. Harpel, P. C., B. R. Gordon, and T. S. Parker. 1989. Plasminogen catayzes binding of lipoprotein(a) to immobilized fibrinogen and fibrin. Proc. Natl. Acad. Sci. USA. 86:3847-3851.

34. Rath, M., A. Niendorf T Reblin, M. Dietel, H. Krebber, and U. Beisiegel. 1989. Detection and quantification of lipoprotein(a) in the arterial wall of 107 coronary bypass patients. Arteriosclerosis. 9:579-592.

35. Cushing, G., J. Gaubatz, M. Nava, B. Burdick, T. Bocan, J. Guyton, D. Weilbaecher, M. DeBakey, G. Lawrie, and J. Morrisett. 1989. Quantitation and localization of apolipoproteins (a) and $B$ in coronary bypass vein grafts resected at reoperation. Arteriosclerosis. 9:593-603.

36. Rappolee, D. A., D. Mark, M. J. Banda, and Z. Werb. 1988. Wound macrophages express TGF- $\alpha$ and other growth factors in vivo. Science (Wash DC). 241:708-712.

37. Diez, E., B. Fernandez, C. Martin, P. Zamorano, and A. Schuller. 1989 Acetylated low density lipoproteins promote the release and metabolism of arachidonic acid by murine macrophages. Biochim. Biophys. Res. Commun. 151:461-467.

38. Wilcox, J. N., K. M. Smith, S. M. Schwartz, and D. Gordon. 1989. Localization of tissue factor in the normal vessel wall and in the atherosclerotic plaque. Proc. Natl. Acad. Sci. USA. 86: 2839-2843. 